\title{
Género, tecnología y educación: Un estudio de caso sobre las diferencias de género en el uso de las $\mathrm{TIC}^{1}$
}

\author{
Renato Guevara-Ayón \\ Pontificia Universidad Católica del Perú \\ renato.guevara@pucp.edu.pe
}

Recibido: 15/04/2019

Aprobado: 08/03/2020

1. Esta investigación fue ganadora del Premio al Inicio de la Investigación (PAIN) 2018 de la PUCP otorgado por el Vicerrectorado Académico a través de la Dirección de Gestión de la Investigación (DGI). El presente artículo está basado en el informe final elaborado para la DGI. 


\title{
Género, tecnología y educación: Un estudio de caso sobre las diferencias de género en el uso de las TIC
}

\begin{abstract}
Resumen
El presente trabajo busca explorar las diferencias de género en el uso de las tecnologías de la información y comunicación (TIC) en el segundo grado de secundaria de un colegio privado mixto en Lima, Perú, que posee un modelo de integración de las TIC de 1:1 (un dispositivo digital por persona). Mediante una aproximación metodológica de estudio de caso y a partir de diversos métodos tanto cuantitativos - encuesta - como cualitativos - observaciones en el aula y entrevistas semiestructuradas-, se evidenciarán las diferencias de género en los usos que les dan los hombres y las mujeres a los dispositivos digitales (chromebooks) y cómo estos se relacionan con los estereotipos de género existentes. El estudio concluye que, mientras hay ligeras diferencias de género en el "uso operacional", existen marcadas diferencias en el "uso creativo" y "uso recreativo". Además, se identificó la existencia de tres clases de estereotipo de género en relación con el uso de las TIC: en el ámbito académico, en el ámbito creativo y en el ámbito tecnológico. De esta forma, se corrobora que, con la incorporación de las tecnologías en el aula, no hay una superación de ciertos estereotipos tradicionales de género, sino que se mantiene la reproducción de estos.

Palabras clave: 1:1, tecnologías de la información, estereotipos de género, adolescencia, colegio privado
\end{abstract}

\section{Gender, technology and education: A case study of the gender differences in the use of ICT}

\begin{abstract}
This paper explores the gender differences in the ways that students of second grade of high school use ICT. The study has focused on a private and coeducational school in Lima, Perú, that has incorporated the ICT in a model 1:1 (one digital device per student). Through a study-case approach and with quantitative (survey) and qualitative methods (participant observation and semi-structured interview), this paper seeks to demonstrate the gender differences in the use of ICT between boys and girls with digital devices (chromebooks) and how these differences are related to gender stereotypes. While showing a slight difference in the "operational use", the study reveals marked differences in the "creative use" and "recreative use". Furthermore, three gender stereotypes were found in three different fields: academic, creative and technological. Based on these findings, this study suggests that technologies reproduce gender stereotypes.

Keywords: 1:1, Information and Communicational Technologies, Gender Stereotypes, youth, private school
\end{abstract}




\section{Introducción}

Las tecnologías de la información y la comunicación (TIC) constituyen un elemento central en nuestra vida cotidiana, pues el uso de computadoras, teléfonos celulares e Internet se ha expandido. Según los datos de la Encuesta Nacional de Hogares realizada por el Instituto Nacional de Estadística e Informática (INEI), en el año $2018^{2}$, el 69,1\% de personas utilizaron en el último mes un celular propio. De la misma manera, el 33,17\% de los hogares en el $2017^{3}$ contaron con una computadora. En relación con el acceso a Internet, en el año 2018, el 33,7\% de los hogares en el Perú dispusieron del servicio de Internet; no obstante, a finales del mismo año, el 56,2\% de las personas han podido acceder a dicho servicio. A nivel de las escuelas, también, se observa la incorporación de las TIC. Según la Encuesta Nacional a Instituciones Educativas (Enedu) realizada por el INEI, en el 2017, el 90,6\% de las instituciones educativas secundarias urbanas contaron con computadoras de escritorio y el $84,2 \%$ de docentes de nivel secundaria en el ámbito urbano integraron las tecnologías digitales en sus clases.

Con estos datos, se puede corroborar que la importancia de las TIC a nivel educativo cada vez es mayor. Así, como menciona Patricia Ames, "[l]a intensa distribución de equipos TIC en la última década, sumada a una mayor disponibilidad de los mismos en el mercado parece estar cambiando aceleradamente el panorama tecnológico en las escuelas peruanas" (2014, p. 147). En este contexto, estudiar de qué manera dichas tecnologías son apropiadas y utilizadas por los estudiantes se convierte en un tema importante que merece un estudio profundo para evaluar si es que están cumpliendo sus objetivos: ser herramientas eficientes para la transmisión de conocimiento hacia las nuevas generaciones.

En esa línea, la presente investigación aborda las diferencias que se generan entre hombres y mujeres al utilizar las TIC dentro de la escuela, así como su relación con los estereotipos de género. Investigaciones en otros contextos han puesto en evidencia las diferencias que existen. Frente a ello, es importante estudiar si es que dicha brecha de género se manifiesta en un contexto como el peruano, marcado por la presencia de estereotipos de género y de machismo (Barreto, García y Asensio, 2013).

\section{Revisión de la literatura}

Desde finales del siglo pasado, y junto con la transición de una "sociedad industrial" a una "sociedad de la información" o "sociedad del conocimiento", el

2. Los porcentajes correspondientes al año 2018 son calculados sobre la base del Trimestre 3 de la Enaho de ese año (actualización más reciente que tenía el INEI al momento en que se redactó el artículo).

3. En el caso de los porcentajes para el año 2017, estos fueron calculados a partir de la data anual de la Enaho de ese mismo año. 
interés por realizar estudios sobre la incorporación de las tecnologías en diferentes ámbitos de la vida social ha aumentado. La educación no ha estado exenta de este proceso y la incorporación de las TIC dentro del sistema educativo constituye un fenómeno de estudio importante. Para Area (2005), las primeras investigaciones sobre el tema se enfocaron en estudios de corte experimental y enfocados en los resultados que traía las tecnologías en la educación (p.e., notas, calificaciones, competencias, etc.). En los últimos años, la producción científica se ha centrado en los usos y las percepciones que diferentes actores (alumnos/as, docentes y padres) poseen sobre estas herramientas dentro del entorno educativo (Area, 2005).

En el ámbito internacional, existe una cantidad considerable de estudios sobre el acercamiento de los estudiantes a las tecnologías, como los usos que les dan a Internet (Trinidad y Zlachesvsky, 2013; Basile y Linne, 2013), a las computadoras (Area, 2010; Cussó, 2014; Cussó-Calabuig et al., 2017) y a las tablets (Buendía García et al., 2016), con distintos resultados, de acuerdo con el contexto aplicado. De manera más reciente, han surgido investigaciones que resaltan las diferencias de género en el uso de estos dispositivos (Gargallo-Castel, Esteban-Salvador y Pérez-Sanz, 2010; Cussó 2014; Morris y Trushell, 2014; Pechtelidis, Kosma y Chronaki, 2015).

Si bien algunas de estas investigaciones dan cuenta de una reducción de la brecha de género (Schaumburg, 2001) o - en todo caso- la falta de diferenciación del uso por género (Cussó, 2014), la tendencia apunta hacia la existencia de diferencias (Morris y Trushell, 2014). Los estudios más recientes de Castro Balsa y Trigo (2017), y Suana (2018) muestran resultados similares en dos contextos diferenciados (España e Indonesia, respectivamente): aunque ambos mencionan que la brecha digital de género (gender gap) parece ser superada, sobre todo en lo que respecta al acceso, persisten diferencias en los tipos de usos. Por un lado, Castro Balsa y Trigo evidencian que las mujeres emplean más las tecnologías para realizar trabajos escolares que los hombres y usan procesadores de texto con mayor frecuencia, mientras que los hombres tienden a usar procesadores numéricos (hojas de cálculo). Por otro, Suana muestra que las mujeres emplean las tecnologías en mayor medida para cuestiones académicas (búsqueda de información sobre temas de física), mientras que los hombres las utilizan más en el ámbito de entretenimiento (videos y animaciones de física).

Asimismo, existen estudios que relacionan la forma como los estereotipos de género moldean o pueden moldear las diferencias de uso de las TIC entre hombres y mujeres (Pechtelidis, Kosma y Chronaki, 2015; Ferreira, 2017). En ellos, se asocia al género masculino con un mayor conocimiento de las tecnologías y mayores habilidades tecnológicas, mientras que a las mujeres se las asocia, en mayor medida, con el desarrollo de habilidades comunicativas (redes sociales, uso del celular, etc.) y con poco conocimiento sobre temas tecnológicos. Una contribución de estas investigaciones es que evidencian que los

estereotipos son aceptados por ambos géneros. 
En el contexto peruano, las investigaciones relacionadas a las TIC y la educación en los últimos años han aumentado. Sin embargo, se han enfocado en la evaluación de los efectos que han tenido diferentes programas tecnológicos incorporados por el Estado en los colegios (Trinidad, 2005; Santiago et. al, 2010; Gutiérrez García, 2010), el uso de tecnologías para la mejora del rendimiento académico (Evaristo Chiyong et al., 2016; Choque, 2009), y los usos de las TIC por parte de los niños y las niñas en la escuela (Ames, 2014). De estos casos, el único que pone énfasis en el género como variable central es el trabajo de Trinidad y Zlachesvsky (2013). Estos autores incorporan las variables de género y clase como ejes principales en su análisis del uso y del disfrute de Internet en niños entre ocho y diez años en Argentina, Perú y Paraguay. Entre sus resultados, resaltan que, a nivel de género, mientras los hombres prefieren escoger videojuegos de violencia, armas y fútbol, las mujeres optan por aquellos de moda, vestimenta y cocina.

Asimismo, se pueden encontrar algunas investigaciones en el ámbito rural $^{4}$, como el trabajo de Barreto, García y Asensio (2013), y el de Morales (2018). Los primeros estudian el uso de celulares e Internet en dos centros poblados de Arequipa y Piura. El segundo se concentra en las desigualdades en el uso de las tecnologías en un centro poblado en Lambayeque. Ambos coinciden en que existen impedimentos a los que se enfrenta el género femenino para tener acceso a las tecnologías, pues el espacio tecnológico (como una cabina de Internet) es asociado con un entorno masculino. Una barrera adicional para acceder a un dispositivo móvil es el dinero. En muchas ocasiones, las jóvenes no cuentan con este, pues se encuentran bajo la tutela de sus padres y/o esposos, $\mathrm{o}$ - en su defecto- se dedican a labores domésticas no remuneradas.

En síntesis, se puede observar una escasez de investigaciones sobre el tema en el ámbito peruano. Si bien el interés por las tecnologías ha sido abordado por diversos autores y autoras, son pocos los casos que han tomado la variable género como eje principal. Tampoco, existen investigaciones que vinculen las diferencias de género en el uso de las TIC con los estereotipos de género, a pesar de que este es un tema importante para entender el papel de las tecnologías en la socialización escolar.

\section{Pregunta y objetivos de investigación}

Sobre la base de este vacío en la literatura, el presente artículo se pregunta de qué manera los estereotipos de género influyen en el uso de las tecnologías de la información y la comunicación (TIC) por parte de alumnos y alumnas de

4. De estas dos investigaciones, la de Barreto, García y Asensio (2013) no está enfocada en la escuela, pero sí en jóvenes. El estudio de Morales (2018), por su parte, incorpora observaciones en la escuela; no obstante, su público objetivo no se reduce a los niños y las niñas, sino que compara diferentes generaciones y el uso que les dan a las tecnologías. 
segundo grado de secundaria de un colegio privado limeño. De esta pregunta principal, se desprenden tres preguntas específicas: ¿Cuáles son las diferencias que existen en el uso de las chromebooks (laptops) entre alumnos y alumnas?, ¿cuáles son las diferentes percepciones de los estudiantes en lo que respecta al uso de las chromebooks?, ¿cuáles son los estereotipos de género que los alumnos y las alumnas muestran sobre el uso y la percepción de las TIC?

El presente artículo cuestiona la visión de las TIC como herramientas inclusivas que ayudan a superar las desigualdades de género en un entorno pedagógico. Como se podrá observar a lo largo de esta investigación, las tecnologías por sí mismas no generan mayor equidad entre los y las estudiantes, pues su incorporación en contextos con desigualdades, las potencia como vehículo de reproducción de estereotipos de género ya existentes, antes que de transformación de dichas brechas.

Para empezar, se puede observar que existen diferencias de género en el uso de las tecnologías (chromebooks y computadoras). El aspecto a resaltar es que este uso diferenciado se ve influenciado por los estereotipos tradicionales de género que no solo los y las estudiantes reproducen, sino que los mismos docentes y la escuela generan a través de diversas prácticas. Entre dichos estereotipos, se encuentran la noción de que las mujeres son más detallistas que los hombres; que, académicamente, son buenas, mientras que los hombres son distraídos; y que los hombres tienen más habilidades en el ámbito tecnológico que las mujeres.

\section{Descripción y contextualización del caso}

Se ha seleccionado un colegio privado de clase media alta en la ciudad de Lima en Perú, que posee un modelo de integración tecnológico de 1:1; es decir, incorpora un dispositivo electrónico por cada estudiante en todas sus asignaturas. Si bien han existido proyectos similares aplicados por el Minedu (Proyecto Huascarán y "One Laptop Per Children"), en la actualidad, estos no están vigentes. En este sentido, el colegio representa un caso paradigmático, al ser uno de los pocos que sigue operando con este modelo.

El colegio seleccionado es católico y ofrece los ciclos desde pre kinder (cuatro años) hasta quinto grado de secundaria (entre dieciséis y diecisiete años). Esta institución ha educado a hombres desde su fundación a fines del siglo XIX y, desde el año 2010, incluyó a mujeres. Así, se convirtió en la primera institución coeducativa que la orden religiosa dirige a nivel nacional. Ello implica que su propuesta pedagógica tiene que cumplir, por un lado, con los estándares establecidos por el Ministerio de Educación a través del Currículo Nacional de Educación Básica (2017) y, por otro, desarrollar los valores que la orden religiosa plantea, expresados en un Currículo Común (2011)5. Si bien el

5. Para mantener el anonimato requerido por la institución educativa, no se colocará la referencia bibliográfica de este texto. 
Currículo Nacional posee dos competencias enfocadas en el desarrollo tecnológico, el Currículo Común no hace alusión a ninguna.

A pesar de que el Ministerio promueve el uso de tecnologías en el aula, la incorporación de este proyecto surgió en el momento en que el colegio decidió renovar su plataforma tecnológica (correo, almacenamiento) por la de Google. Dicha empresa le ofreció su paquete "G suite for education", un servicio destinado a instituciones educativas para incorporar tecnologías en el aula, tanto a nivel de software (programas, almacenamiento, red) como de hardware (chromebooks). Las chromebooks son pequeñas laptops (netbooks) que están equipadas con el sistema operativo de Google (Chrome OS). Estas funcionan con conexión a Internet para acceder a Google Docs (procesador de textos), Google Sheets (procesador numérico), Gmail (correo) y diversos aplicativos para mantener conectados a docentes, estudiantes y administrativos.

Este proyecto fue incorporado progresivamente en las aulas, pese a que los objetivos y el fundamento pedagógico no fuesen difundidos a toda la comunidad educativa. Como consecuencia, no todo el equipo docente recibió la propuesta con optimismo. El proyecto inició en el 2016 con la implementación de un Aula de Innovación Pedagógica que contaba con una pizarra táctil y 30 chromebooks para que el personal docente que las reservara pudiera utilizarlas. $\mathrm{Al}$ año siguiente, se incorporó un modelo piloto en tercero y cuarto de secundaria $^{7}$ (una chromebook por estudiante), y, en el 2018, segundo y quinto de secundaria ingresaron al modelo como un proyecto permanente. Para el 2019, el colegio planeó generalizar el modelo en todo el nivel de secundaria y en sexto de primaria.

\section{Marco conceptual}

\section{Uso de las tecnologías de la información y comunicación (TIC)}

Las tecnologías de la información y comunicación, conocidas como las "TIC", abarcan diversos tipos de dispositivos electrónicos que median la comunicación a distancia entre individuos. Ejemplos de estas son las computadoras, tablets, smartphones, entre otros. Los usos que se les dan a estas tecnologías varían de acuerdo con los usuarios y contextos. Algunos autores han realizado tipologías de usos, sobre las cuales se elaborará una propia a partir de la evidencia encontrada en el campo. Hernández et al. (2015) plantea nueve tipos de uso de las TIC, de los cuales este estudio recogerá cuatro: uso de las TIC como "herramienta para el aprendizaje técnico", "como medio de consulta de

6. Para información más detallada, se puede consultar el sitio web: https://edu.google. com/intl/es-419/products/gsuite-for-education/?modal_active=none

7. Por lo conversado con algunos docentes, el piloto no fue evaluado y los resultados no fueron compartidos con la comunidad educativa. Asimismo, el proyecto no cuenta con una línea de base con la cual comparar la aplicación de las tecnologías. 
información", "como herramienta para procesar información" y "como medio de recreación". Los primeros tres tipos se sintetizan en una sola categoría que se denominará "uso operacional de las TIC", que abarca las diferentes habilidades básicas que los estudiantes realizan con las tecnologías de forma técnica (ingresar a la web, abrir un programa determinado, etc.). La cuarta categoría se mantendrá estática y hará referencia a las actividades que los estudiantes emplean para su recreación. Finalmente, el tercer tipo de uso será al que Márquez (1999), citado por García y Gonzáles (s.f.), se refiere como "función creativa". El uso creativo de las TIC alude a que los/as estudiantes pueden desplegar su imaginación, y utilizar su creatividad para crear productos novedosos que transmitan algún mensaje o idea.

\section{Estereotipos de género}

La definición de estereotipos es diversa; sin embargo, se puede establecer un consenso en la literatura en torno a que suponen una reducción o una simplificación de la realidad sobre la base de ciertas características atribuidas a un grupo social (Talbot, 2003; Belmonte y Guillamón, 2008; Hall, 2010; Rodríguez-López, 2015). De esa manera, se tomará en cuenta, principalmente las concepciones sobre estereotipos de Hall (2010) y Talbot (2003). Hall (2010), basándose en las ideas de Dyer, establece una diferencia entre "tipo" y "estereotipo": mientras el primer concepto se emplea para clasificar al mundo (necesidad humana intrínseca), el segundo hace alusión a una reducción de las personas a ciertas características que se toman como fijas y casi como naturales. En ese marco, el autor señala que los estereotipos "[...] retienen unas cuantas características 'sencillas, vividas, memorables, fácilmente percibidas y ampliamente reconocidas' acerca de una persona, reducen todo acerca de una persona a esos rasgos, los exageran y simplifican y los fijan sin cambio o desarrollo para la eternidad" (Hall, 2010, p. 429-430). No obstante, los estereotipos no solo reducen la realidad, sino que la dividen dicotómicamente, a través de fronteras simbólicas entre aquello que el grupo define como "normal" y "anormal". De esta manera, se construye un "nosotros" (pertenecientes al grupo), en oposición a un "otro extraño", a quien se margina y discrimina.

Siguiendo una postura similar, Talbot (2003) establece una diferenciación entre el tipo social y la estereotipación ${ }^{8}$ : la primera sirve para categorizar el mundo y la segunda para reducirlo a unas cuantas características. En esa línea, la autora define a los estereotipos de género como prescripciones ideológicas o normas de comportamiento que actúan fuertemente en los individuos (2003, p. 473). A esta noción se debe incorporar la idea de González Gabaldón (1999), quien establece que "los sucesos que confirman las expectativas estereotipadas previas son recordados mejor que los que las contradicen" (p. 81). Es decir,

8 En inglés, usa las categorías de social typing para "tipo social” y stereotyping para "estereotipación". 
cualquier acción que corrobore el estereotipo será tomada en mayor consideración (para la validación de estereotipo) que aquellas que lo contradicen.

En el presente estudio, se ha elaborado una tipología propia sobre los estereotipos de género que se sustenta en la información recolectada durante el trabajo de campo. El planteamiento dicotómico de los estereotipos se basa en la idea de Hall (2010) sobre la creación de fronteras simbólicas entre el "nosotros" y el "otro" explicada anteriormente. No obstante, los estereotipos planteados no son estáticos y, por parte de los estudiantes, existen ciertas resistencias que los cuestionan. A pesar de ello, se considera que son categorías útiles para el análisis del presente estudio.

\section{Metodología}

La presente investigación se enmarca dentro de lo que, en Ciencias Sociales, se conoce como un estudio de caso. El estudio de caso permite enfocarse en un conglomerado pequeño de datos y explorarlos a profundidad para identificar relaciones que en un análisis más superficial no se podrían encontrar. Se seleccionó el caso debido a su representatividad como un modelo de integración tecnológico 1:1 en el Perú, pues es uno de los pocos centros educativos que incorpora este modelo en la actualidad. Se empleó un enfoque de método mixto cuan $\rightarrow$ CUAL $^{9}$ (Johnson y Onwuegbuzie, 2004) a partir de dos fases de recojo de información: una primera cuantitativa y una segunda cualitativa. Es importante resaltar que el análisis cualitativo es el predominante en la investigación y el cuantitativo sirve de manera complementaria.

Para el recojo de la información ${ }^{10}$, se emplearon tres métodos: encuesta, observación participante y entrevistas semiestructuradas. La encuesta, de carácter exploratorio, se dividió en tres secciones y tuvo como finalidad recolectar información general sobre el grupo de estudiantes. En la primera sección, se realizaron preguntas generales sobre datos de los alumnos y las alumnas (edad, sección, edad en el inicio de las TIC, etc.). En la segunda sección, se preguntó sobre el uso que se les daba a las chromebooks en el colegio (actividades que realizaban, programas, asignaturas con mayor uso de, etc.). Finalmente, en la tercera sección, se plantearon doce afirmaciones (seis relacionadas a los hombres y seis relacionadas a las mujeres) sobre algunos usos que los hombres

9. El enfoque mixto cuan $\rightarrow$ CUAL (Johnson y Onwuegbuzie, 2004) hace referencia a la utilización de una metodología cuantitativa en una primera fase de la investigación y una metodología cualitativa en la fase posterior. Las mayúsculas (CUAL) manifiestan que el análisis cualitativo es el principal y que el cuantitativo sirve como complemento. El hecho de que la metodología cuantitativa se encuentre en primer lugar significa que sus resultados contribuyeron a nutrir y modificar la sección cualitativa.

10. El proceso de recojo de información se realizó entre agosto y diciembre del año 2018, con algunas entrevistas complementarias a inicios del 2019 (enero y febrero). 
y las mujeres le dan a la tecnología. Estas afirmaciones se plantearon para saber qué tan de acuerdo o en desacuerdo se encontraban los/as estudiantes con los estereotipos de género presentados. Dichos estereotipos consistieron en afirmaciones positivas y negativas sobre la facilidad en el uso de herramientas tecnológicas, construidos sobre la base de la literatura revisada. Para ello, se utilizó una escala Likert con cinco afirmaciones que van desde "Muy de acuerdo" hasta "Muy en desacuerdo". Los doce ítems planteados se pueden observar a continuación:

Tabla 1. Afirmaciones sobre el uso de las tecnologías

\begin{tabular}{|c|c|c|c|}
\hline Mujer positivo & Mujer negativo & Hombre positivo & Hombre negativo \\
\hline $\begin{array}{l}\text { M1: Las chicas son } \\
\text { buenas con los pro- } \\
\text { gramas de edición de } \\
\text { videos. }\end{array}$ & $\begin{array}{l}\text { M4: Las chicas no son } \\
\text { buenas en los cursos } \\
\text { de informática. }\end{array}$ & $\begin{array}{l}\text { H1: Los chicos son } \\
\text { buenos en los cursos } \\
\text { de informática. }\end{array}$ & $\begin{array}{l}\text { H4: A los chicos les } \\
\text { cuesta crear presenta- } \\
\text { ciones de Power Point } \\
\text { de forma creativa. }\end{array}$ \\
\hline $\begin{array}{l}\text { M2: Las chicas son } \\
\text { buenas utilizando } \\
\text { programas como } \\
\text { Word, Power Point, } \\
\text { Google Docs, etc. }\end{array}$ & $\begin{array}{l}\text { M5: A las chicas se } \\
\text { les hace difícil apren- } \\
\text { der a programar }\end{array}$ & $\begin{array}{l}\text { H2: A los chicos se } \\
\text { les hace fácil apren- } \\
\text { der programas de } \\
\text { computación. }\end{array}$ & $\begin{array}{l}\text { H5: A los chicos se } \\
\text { les hace más difícil } \\
\text { editar videos. }\end{array}$ \\
\hline $\begin{array}{l}\text { M3: Las chicas son } \\
\text { más creativas para } \\
\text { crear presentaciones } \\
\text { en Power Point que } \\
\text { los chicos. }\end{array}$ & $\begin{array}{l}\text { M6: Las chicas no } \\
\text { podrían crear un } \\
\text { videojuego. }\end{array}$ & $\begin{array}{l}\text { H3: A los chicos se } \\
\text { les hace fácil apren- } \\
\text { der a programar. }\end{array}$ & $\begin{array}{l}\text { H6: A los chicos no } \\
\text { les gusta decorar mu- } \\
\text { cho sus presentacio- } \\
\text { nes en Power Point. }\end{array}$ \\
\hline
\end{tabular}

Fuente: Elaboración propia

Se realizó un piloto de la encuesta a cinco estudiantes para evaluar el diseño del cuestionario (orden, tiempo, coherencia, etc.) y, así, realizar las modificaciones correspondientes. La encuesta se aplicó a un total de 73 estudiantes ${ }^{11}$ a través de la plataforma Google Forms para facilitar su transcripción. Los resultados contribuyeron a seleccionar las asignaturas que se observaron en la segunda fase de campo. En dicha fase, se preguntó por aquellas asignaturas en que el uso de las tecnologías fuese más recurrente. Asimismo, los resultados de la tercera sección ayudaron a triangular la información sobre los estereotipos de género.

11. En un primer momento, la encuesta pretendió ser un censo a todos los estudiantes de la población ( $\mathrm{N}=120)$; sin embargo, no todas las familias accedieron a dar el consentimiento para que sus hijos/as pudieran participar de la encuesta. Por ello, esta solo se aplicó a una muestra de 73 estudiantes. 
En la segunda fase de campo, se realizó observación participante y entrevistas semiestructuradas. La observación participante se llevó a cabo de manera sistemática durante aproximadamente dos meses en las asignaturas de Science (Ciencias Naturales, dictado en inglés) e Informática (Cómputo) ${ }^{12}$, pues fueron los cursos que, según el grupo de estudiantes, tenían un uso intensivo de las tecnologías. Además, disciplinas como Ciencias Naturales y Cómputo han sido asociadas con el género masculino (Pérez Sedeño, 2008; Ferreira, 2017), y, por tanto, pueden constituir entornos con sesgos y estereotipos de género que podrían afectar (en favor de unos y en perjuicio de otros) el uso que los hombres y mujeres les dan a las tecnologías.

Por otro lado, las entrevistas semiestructuradas fueron aplicadas a veinte estudiantes para obtener sus percepciones sobre el uso de las tecnologías en el aula (uso personal, uso de sus compañeros/as, actividades que realizan). Asimismo, se buscaba identificar la presencia de estereotipos de género en sus discursos.

En paralelo, se aplicaron cuatro entrevistas ${ }^{13}$ a docentes sobre cómo implementaban las TIC en sus cursos, así como las percepciones que tenían sobre el uso que sus estudiantes les dan en clases. Por último, se realizaron preguntas sobre la forma como el equipo docente concibe el papel del hombre y la mujer en los procesos de aprendizaje, y qué facilidades y/o dificultades pueden presentar con el uso de las tecnologías.

\section{Procesamiento y análisis de información}

Las encuestas fueron resueltas de forma anónima por cada estudiante en la plataforma "Google Forms", que almacena las respuestas en una hoja de cálculo de Google, la cual se descargó para los análisis descriptivos. El análisis de los datos fue realizado en el programa R Studio y se utilizó un análisis estadístico descriptivo básico (media, moda, porcentajes), con el cual se construyeron tablas de frecuencias. Durante las observaciones en el aula, se tomaron notas de campo de cada una de las sesiones. Estas notas fueron transcritas, codificadas y analizadas en base a la operacionalización realizada. Por su parte, en las

12. Si bien, en un principio se pensó observar clases de Matemática y Comunicación (la primera porque encaja dentro de los cursos que típicamente se han asociado a los hombres y la segunda porque la encuesta evidenció que era uno de los cursos con mayor uso de tecnologías), al presenciar algunas sesiones, se pudo corroborar que el uso de chromebooks era poco frecuente, por lo que se las descartó finalmente de una observación sistemática. Aun así, la observación sirvió de referencia al momento de analizar la información.

13. Se entrevistó a cuatro docentes: tres hombres y una mujer. El motivo por el cual el número de mujeres entrevistadas es menor responde a que las profesoras no accedieron a brindar las entrevistas, ya sea por falta de tiempo y/o por otros motivos personales. 
entrevistas, se le asignó un pseudónimo a cada persona entrevistada y se transcribieron sus respuestas en Google Docs. Posteriormente, se codificó y analizó cada una de las entrevistas para luego realizar una comparación con el fin de encontrar situaciones similares y/o conflictos entre las respuestas. Finalmente, toda la información (encuesta, notas de campo y entrevistas) fue comparada (triangulación) para tener un resultado con mayor validez.

\section{Características de la muestra}

La muestra estuvo compuesta por estudiantes de segundo grado de secundaria (trece a catorce años de edad) del colegio en mención, quienes estaban divididos en cuatro salones (secciones $\mathrm{A}, \mathrm{B}, \mathrm{C}$ y $\mathrm{D}$ ) con un número de treinta estudiantes por sección. Se seleccionó esta muestra, debido a que son el primer grupo mixto al que el colegio ha aplicado este modelo tecnológico y se consideró importante entender los efectos que la tecnología puede tener en la primera promoción de hombres y mujeres. Por ser la primera promoción coeducativa, el número de mujeres por cada salón es reducido (aproximadamente, siete mujeres en un salón de treinta estudiantes). En ese sentido, es importante tener en cuenta que esta diferencia proporcional podría afectar la interpretación que se les da a los datos. Por ello, las interpretaciones presentadas a continuación no pueden ser generalizadas, pero sí pueden brindar un primer acercamiento a las diferencias que se generan en la escuela con las tecnologías y así alentar a que se realicen más investigaciones sobre el tema en casos con menor desproporción entre hombres y mujeres.

\section{Resultados}

La organización de los resultados está dividida en tres secciones. Cada una de ellas responde a una de las preguntas específicas que se plantearon líneas más arriba.

\section{Las diferencias en el uso de las TIC}

\section{- Uso operacional}

Por un lado, en el curso de Science (Tabla 2), las mujeres afirman tener mayor dificultad (24\%), en contraste con los hombres (2,1\%), especialmente en el uso de hojas de cálculo de Google ${ }^{14}$ (Google Sheets). Por su parte, en el curso de Informática, el nivel de dificultad para ambos géneros aumenta, pues el 28\% de mujeres y el 22,9\% de hombres (Tabla 3) afirman tener dificultades con los programas utilizados en la asignatura.

14. Este programa de Google para sistematización de datos (sobre todo, numéricos) es el equivalente a Microsoft Excel. 
Tabla 2. Dificultad en el uso de programas en el curso de Science

\begin{tabular}{ccccccc}
\hline \multirow{2}{*}{ Género } & \multicolumn{3}{c}{ N } & & \multicolumn{3}{c}{$\%$} \\
\cline { 2 - 7 } & No & Sí & Total & No & Sí & Total \\
\hline Femenino & 19 & 6 & 25 & 76,0 & 24,0 & 100 \\
Masculino & 47 & 1 & 48 & 97,9 & 2,1 & 100 \\
\hline
\end{tabular}

Fuente: Elaboración propia.

Tabla 3. Dificultad en el uso de programas en el curso de Informática

\begin{tabular}{ccccccc}
\hline \multirow{2}{*}{ Género } & \multicolumn{3}{c}{ N } & & \multicolumn{3}{c}{$\%$} \\
\cline { 2 - 7 } & No & Sí & Total & No & Sí & Total \\
\hline Femenino & 18 & 7 & 25 & 72,0 & 28,0 & 100 \\
Masculino & 37 & 11 & 48 & 77,1 & 22,9 & 100 \\
\hline
\end{tabular}

Fuente: Elaboración propia.

El aumento en la cantidad de estudiantes que manifiestan tener dificultad en el curso de Informática se debe al poco conocimiento que poseen con el programa Construct ${ }^{15}$, pues es una plataforma con la cual no han trabajo antes y que requiere del uso de comandos complejos para su ejecución. Esta poca familiaridad les genera un gran número de dudas - por ejemplo, cómo darle movimiento a un objeto, cambiar de escena, etc. - a tal punto de que el docente no puede responderlas todas.

La poca disponibilidad del docente para atender a las dudas de sus estudiantes ha generado que estos recurran a sus pares para solventarlas. Así, surgen figuras como Chispita o Barto, que tienen un dominio sobresaliente de las tecnologías y brindan ayuda a sus demás compañeros. Para el caso de las mujeres, no se ha podido identificar algún personaje icónico con expertise que tenga un reconocimiento similar entre sus compañeras. Sin embargo, existen algunas alumnas que ayudan a otras:

Una de las chicas que está sentada en la máquina 16 va donde las chicas del grupo ganador [juego de misterio, máquina 26] y les pide ayuda en un par de temas. Ella va y lo soluciona, y, luego, regresa a su sitio. (Registro de observación participante 16, clase de informática)

15. Es un software de edición de videojuegos online y gratuito. Para mayor información, se puede consultar su web https://www.construct.net/en. 
Esta falta de referentes femeninos "visibles" se puede deber a la poca cantidad de mujeres, lo que limitaría la posibilidad de encontrar una mayor cantidad de alumnas que se vuelvan referentes. Sin embargo, las mujeres sí reconocen, como en el testimonio anterior, que tienen compañeras con mayor dominio del programa, solo que no son reconocidas por sus pares masculinos, en la misma medida que los hombres sí lo hacen entre ellos.

Si bien en los programas numéricos se encuentran algunas diferencias entre hombres y mujeres, en el resto de programas utilizados por los/as estudiantes - como Google Docs ${ }^{16}$ y Google Slides ${ }^{17}$-, no se observan mayores dificultades. Esto se debe a que cuentan con experiencia previa en el uso de programas similares (Microsoft Word, Power Point) en grados pasados. En este sentido, para la mayoría de estudiantes, las chromebooks facilitan el estudio, puesto que pueden tomar apuntes con mayor velocidad:

Entonces, ahora que usamos chromebooks es todo un poco más sencillo. [...] este, nada más tenemos que tipear y [ininteligible] en sexto grado con Nardita aprendimos esto de la mecanografía rápida [...] podemos hacer resúmenes cosas más fáciles y, en vez de tener que estar copiándolo en el cuaderno y ponerlo bonito, este con la chromebook de frente lo detallamos, y luego lo imprimimos y estudiamos de ahí. (entrevista a Álvaro, estudiante)

La acción del tipeo rápido es una evidencia de la comodidad y la facilidad con la que los alumnos y las alumnas se desenvuelven, a un nivel operacional, con las tecnologías. Denota, además, el desarrollo de habilidades motoras (movimiento veloz de los dedos) que solo se adquieren con el uso recurrente y la práctica en dispositivos digitales. En este sentido, se puede afirmar que se presentan algunas leves diferencias de género en el uso operacional a nivel de los programas numéricos y de programación (Google Sheets y Construct), mas no en programas de procesamiento de textos y diseño de presentaciones.

\section{- Uso recreativo}

Se observa una gran diferencia entre hombres y mujeres en relación con el uso recreativo que les dan a las chromebooks y computadoras durante sus clases. En algunos momentos, el docente del curso dispone de algunos minutos sin ninguna actividad y se las asigna a sus estudiantes para que hagan uso libre de ese tiempo. En estos casos, se identifican diferencias en lo que respecta a los programas o aplicativos que utilizan. Sobre este punto, una estudiante comenta:

16. Google Docs es un procesador de texto online similar a un Microsoft Word para tomar apuntes de las clases o presentar trabajos escritos.

17. Google Slides es un software para realizar presentaciones online similar a un Microsoft Power Point. Con él, se pueden generar exposiciones y presentaciones para los cursos. 
Yo creo que sí. Las chicas lo utilizan más para buscar información acerca de, no sé, este, $(.)^{18}$ cómo poderse hacer un peinado; buscan en Internet, o en Pinterest ${ }^{19}$, por ejemplo, que es una aplicación muy utilizada. Buscan cómo hacer algo. En cambio, los chicos es más que se pegan a los juegos. O también algo que es para los dos, que están bien pegados, es la música. Que ya todos utilizan eso. (Entrevista a Aissa, estudiante)

Otro alumno señala: "En clase, yo veo que los chicos entran a jugar, a videojuegos, a las páginas. $\mathrm{io}^{20}$. y las chicas, en vez de entrar, eso entran a Netflix $^{21}$, YouTube ${ }^{22}$ y eso a ver películas en vez de jugar" (entrevista a Gustavo 2B).

Como lo comenta Aissa, las mujeres prefieren emplear el Internet para buscar temas que "comúnmente" están relacionados con el género femenino, como la estética - hacerse un peinado, buscar ropa a la moda, etc. - y la cocina. De hecho, más adelante en la entrevista, ella misma explica que también emplea Pinterest para buscar videos sobre cómo preparar ciertos postres y/o platos de forma sencilla. Además, las mujeres prefieren invertir su tiempo libre en mirar series o películas en aplicativos como Netflix, YouTube, o hacer uso de las redes sociales (Facebook, Instagram), a diferencia de los hombres que priorizan los videojuegos en los momentos de ocio.

Si bien existe un uso recreativo en los espacios libres que los profesores y las profesoras permiten, surgen momentos durante las clases regulares en los que dicho uso aparece y se transforma en un medio de distracción para evadir las temáticas de la clase. Las siguientes observaciones de la asignatura de Informática pueden ilustrar lo dicho anteriormente:

Evidentemente, las indicaciones del profesor no son tomadas muy en serio y algunos alumnos hacen cualquier cosa menos avanzar (videos, videojuegos, otros cursos, música, conversar, etc.). Algunos alumnos se paran y se van a ver las computadoras de otros de sus compañeros para

18. El signo (.) denota una pausa de la hablante. A mayor cantidad de puntos al interior del paréntesis, mayor es la pausa.

19. Pinterest es una red social en la que se comparten imágenes y videos sobre diversas temáticas. Para mayor información, se puede visitar su página web: https://www. pinterest.es/.

20. El ".io" es un tipo de dominio de las páginas web, así como el ".com” o el ".net", referente a un lugar geográfico específico (Territorio Británico del Océano Índico).

21. Netflix es una plataforma web en la que el usuario debe pagar una cantidad mensual (aproximadamente, dieciséis soles al mes, equivalente a cinco dólares) para tener acceso a películas y series de diversas categorías. Para mayor información, se puede revisar la página: http://netflix.com/

22. YouTube es una página web en la que los usuarios suben videos de contenido diverso. Para mayor información, se puede consultar la página: https:/www.youtube.com/ 
conversar o para ver videos en conjunto (lo usual es poder observar tres chicos en una misma pantalla). (Registro de observación participante 16 , clase de Informática)

Como se evidencia en las observaciones realizadas, son los hombres quienes más tienden a distraerse en las clases. En cambio, las mujeres siguen las actividades que se les ha indicado, y las veces que se distraen es de forma momentánea y no sostenida a lo largo de la sesión. Un tema importante es que el tipo de distracción entre hombres y mujeres varía, pues, mientras los hombres juegan videojuegos o ven videos sobre estos, las mujeres - por lo generalrealizan tareas de otros cursos o leen:

Es interesante observar que mientras exponían los grupos, había tres chicas que tienen un libro sobre la mesa y estaban leyéndolo. Pareciera como si esa fuera su forma de distraerse o aprovechar el tiempo. En todo caso, igual están dejando de prestar atención a las presentaciones de sus compañeros(as). (Registro de observación participante 11, clase de Science)

Lo observado en clase se corroboró con las entrevistas realizadas a la muestra de estudiantes, quienes mencionaron que existe un grupo de alumnos que dedican parte de su tiempo escolar a jugar videojuegos. Estos videojuegos son en línea y se juegan en vivo contra diferentes jugadores del mundo. Si bien los nombres son distintos, los objetivos son similares: los jugadores tienen que matar a los demás para poder ganar. Son tres los juegos identificados: Surviv. io $^{23}$, Fornite.io (actualmente, eliminado) y Agar.io ${ }^{24}$.

Los grupos de estudiantes que tienen esta afición son conocidos con distintos nombres, como "los gamers", "los alt+tab" o "Team Rocket". Pese a ello, todos hacen referencia a grupos de estudiantes que juegan durante clases. Quienes participan son en su mayoría hombres; sin embargo, según lo que algunos entrevistados comentaron, hay algunas mujeres que también participan, aunque de manera muy reducida (en cantidad) y no es constante (juegan a veces). Por sección (salón), juegan entre una o dos mujeres, lo cual contrasta con el número de hombres, que - se calcula - asciende a siete u ocho.

23. Surviv es un juego online en el que seleccionas un nombre (nickname) y debes matar al resto de jugadores para poder sobrevivir antes de que se agote el tiempo. Quien dura más tiempo es el ganador. Se puede encontrar más información en su página web: http://surviv.io/

24. Agar es un juego online en que el jugador es un círculo de color (varía el color al azar), que debe "comer" al resto de círculos (demás jugadores) para ir aumentando de tamaño y convertirse el número 1 en el ranking. Este juego no tiene fin, salvo cuando un jugador elimina a otro; es decir, cuando lo "come". Para más información, se puede consultar su sitio web: https://agar.io/ 


\section{- Uso creativo}

En cuanto al "uso creativo", también, se pueden encontrar diferencias en dos temas principalmente: en el diseño de presentaciones y en el diseño de los videojuegos que realizaron en grupos para el curso de Informática. Las presentaciones de Google o Google Slides son utilizadas para hacer exposiciones, presentaciones de trabajos, etc. El diseño de las diapositivas (el título, el tipo de texto) varía entre los hombres y las mujeres.

Según los/as estudiantes, existe una dicotomía en la forma como diseñan las presentaciones. Mientras las mujeres se preocupan más por los detalles es decir, por el tipo de letra, el fondo, y que todos estos elementos dialoguen con el contenido-, los hombres solo se preocupan por el contenido que tiene la presentación, sin necesariamente vincularlo con una estética determinada. Esto se puede ver en los siguientes comentarios:

[...] por ejemplo, yo soy una de las más detallistas. Este, yo me fijo bastante en los detalles que pueden tener el PPT. Por ejemplo, los chicos solo agarran un color, no sé el negro, para el color del fondo del PPT, y le ponen una letra cualquiera, la primera letra. Solo escriben toda la información con tal de que esté la información y una foto cualquiera, ya está bien. (entrevista a Aissa, estudiante)

[...] ahmm, yo creo que algunas veces las chicas se enfocan más en los detalles del PPT y, ehmm tratan de decorarlo a su manera, y, y los hombres se basan más en la información, en el contenido, en lo que tiene que tener. (entrevista a Josué, estudiante)

Para una de las alumnas, la dicotomía existente se puede resumir en el hecho de que las mujeres prefieren el color, mientras los hombres prefieren el gris. Es decir, las mujeres elaboran una presentación "más colorida", que, por tanto, atrae más a las personas. En contraste, los hombres diseñan una presentación más sutil, sobria, con colores más grises y oscuros, pues lo que buscan no es necesariamente llamar la atención, sino transmitir el mensaje:

O sea, de repente al momento de hacer trabajos, las chicas buscan más lo que les llame la atención, que capte la atención del público, por ejemplo, imágenes, gráficos, esas cosas. Y los chicos, o sea, es como si dijera gris y color. (entrevista a Alicia, estudiante)

Por su parte, los alumnos y las alumnas del curso de Informática crearon un videojuego que contempló tres aspectos: el diseño de la historia, la creación de los personajes y los paisajes en digital, y la programación. Para ello, se formaron grupos de tres integrantes, en los que a cada miembro se le asignó una de esas funciones. La elección de los miembros y la temática eran libres, y, por 
lo general, los integrantes de los grupos que se formaron eran del mismo género. En los casos que se identificaron grupos mixtos, la división del trabajo por género era clara: ninguna mujer ocupó el cargo de "programación". Además, en estos, la elección de la temática del juego provenía de los hombres, a partir de lo cual se evidenciaba una predominancia de ellos en los campos tecnológicos.

También, se debe anotar que las temáticas de los videojuegos eran distintas entre géneros. Por un lado, los hombres crearon videojuegos de estrategia o de competencia relacionados con batallas ${ }^{25}$, táctica ${ }^{26} \mathrm{y}_{\text {violencia }}{ }^{27}$. Por otro lado, las mujeres optaban por temáticas más variadas, inclusive juegos con cierto grado de violencia, pero se centraron principalmente en estrategia (juegos de obstáculos), farándula (videojuegos que suponían perseguir famosos) y sobre temáticas personales (vida de una adolescente).

La violencia fue un elemento muy recurrente en los videojuegos que los hombres crearon. Ello no se manifestó de forma tan evidente en el caso de las mujeres, en que esta fue un elemento complementario a la historia que cumplía una función narrativa. Es decir, contribuía a que se genere otro tipo de actividades (pasar a un siguiente nivel, tener un villano que dificulte el juego, etc.). En contraste, en el caso de los hombres, el desarrollo de la historia giraba en torno a elementos violentos como el uso constante de armas, superpoderes, asesinatos, entre otros. En ese sentido, en su caso, la violencia se constituía como un elemento central en el desarrollo del videojuego.

\section{Percepción y autopercepción de uso de las tecnologías ${ }^{28}$}

\section{- Percepciones sobre las mujeres}

En las siguientes tablas, se presenta el nivel de aceptación que los alumnos y alumnas manifestaron en la encuesta sobre las afirmaciones acerca de diferentes estereotipos de género que se asocian con el uso de la tecnología entre hombres y mujeres.

25. Por ejemplo, se trataba de juegos en los que se representaba una batalla entre docentes y estudiantes, naves en el espacio, etc.

26. Consistían, por ejemplo, en liberar a la princesa de un conde en la Edad Media, saltar obstáculos (juegos de plataforma), etc.

27. Un ejemplo sería el de juegos en los que se debe matar al enemigo.

28. Todas las tablas de esta sección fueron calculadas a partir de las respuestas de 25 mujeres $(\mathrm{N}=25)$ y de 48 hombres $(\mathrm{N}=48)$. 
Tabla 4. Nivel de aceptación de la afirmación M1:

"Las chicas son buenas con los programas de edición de videos" según género (\%)

\begin{tabular}{lcccccc}
\hline & $\begin{array}{c}\text { Muy en } \\
\text { desacuerdo }\end{array}$ & $\begin{array}{c}\text { En } \\
\text { desacuerdo }\end{array}$ & $\begin{array}{c}\text { Ni de acuerdo } \\
\text { ni en } \\
\text { desacuerdo }\end{array}$ & $\begin{array}{c}\text { De } \\
\text { acuerdo }\end{array}$ & $\begin{array}{c}\text { Muy } \\
\text { de acuerdo }\end{array}$ & Total \\
\hline Femenino & 0,0 & 4,0 & 32,0 & 20,0 & 44,0 & 100.0 \\
Masculino & 0,0 & 4,2 & 37,5 & 54,2 & 4,2 & 100.0 \\
\hline
\end{tabular}

Fuente: Elaboración propia.

Tabla 5. Nivel de aceptación de la afirmación M2:

"Las chicas son buenas utilizando programas como Word, Power Point, Google Docs, etc.", según género $(\%)$

\begin{tabular}{lcccccc}
\hline & $\begin{array}{c}\text { Muy en } \\
\text { desacuerdo }\end{array}$ & $\begin{array}{c}\text { En } \\
\text { desacuerdo }\end{array}$ & $\begin{array}{c}\text { Ni de acuerdo } \\
\text { ni en } \\
\text { desacuerdo }\end{array}$ & $\begin{array}{c}\text { De } \\
\text { acuerdo }\end{array}$ & $\begin{array}{c}\text { Muy } \\
\text { de acuerdo }\end{array}$ & Total \\
\hline Femenino & 0,0 & 0,0 & 24,0 & 24,0 & 52,0 & 100,0 \\
Masculino & 0,0 & 2,1 & 14,6 & 47,9 & 35,4 & 100,0 \\
\hline
\end{tabular}

Fuente: Elaboración propia.

Tabla 6. Nivel de aceptación de la afirmación M3:

"Las chicas son más creativas para crear presentaciones en Power Point que los chicos", según género (\%)

\begin{tabular}{lcccccc}
\hline & $\begin{array}{c}\text { Muy en } \\
\text { desacuerdo }\end{array}$ & $\begin{array}{c}\text { En } \\
\text { desacuerdo }\end{array}$ & $\begin{array}{c}\text { Ni de acuerdo } \\
\text { ni en } \\
\text { desacuerdo }\end{array}$ & $\begin{array}{c}\text { De } \\
\text { acuerdo }\end{array}$ & $\begin{array}{c}\text { Muy } \\
\text { de acuerdo }\end{array}$ & Total \\
\hline Femenino & 0,0 & 8,0 & 24,0 & 16,0 & 52,0 & 100,0 \\
Masculino & 2,1 & 4,2 & 25,0 & 27,1 & 41,7 & 100,0 \\
\hline
\end{tabular}

Fuente: Elaboración propia.

Las afirmaciones positivas sobre las mujeres (tablas 4,5 y 6 ) reflejan la tendencia hacia una aceptación elevada de que ellas tienen las capacidades para utilizar programas como Word, Power Point (M2), y programas de edición de videos (M1). Además, muestran la noción de que poseen una creatividad más desarrollada que los varones (M3), pues, según los encuestados de ambos géneros, la aceptación ("De acuerdo" y "Muy de acuerdo") sobrepasa el 60\%. Sin embargo, es importante anotar que la mayor aceptación se concentra en el grupo femenino. Esto se puede evidenciar en tanto el $44 \%$ de mujeres se 
encuentra "Muy de acuerdo" con la afirmación M1, mientras que en el caso de los hombres solo es del 4,2\%. Una situación similar se observa frente a las afirmaciones M2 (la diferencia entre géneros es de 16,6\%) y M3 (la diferencia es de $10,3 \%)$. De este modo, se refleja que, a pesar de que exista cierto grado de aceptación por parte de los hombres frente a estas afirmaciones, no lo están en su máxima expresión.

Tabla 7. Nivel de aceptación de la afirmación M4:

"Las chicas no son buenas en los cursos de informática" según género (\%)

\begin{tabular}{ccccccc}
\hline & $\begin{array}{c}\text { Muy de } \\
\text { acuerdo }\end{array}$ & $\begin{array}{c}\text { De } \\
\text { acuerdo }\end{array}$ & $\begin{array}{c}\text { Ni de acuerdo } \\
\text { ni en } \\
\text { desacuerdo }\end{array}$ & $\begin{array}{c}\text { En } \\
\text { desacuerdo }\end{array}$ & $\begin{array}{c}\text { Muy en } \\
\text { desacuerdo }\end{array}$ & Total \\
\hline Femenino & 0,0 & 8,0 & 28,0 & 24,0 & 40,0 & 100,0 \\
Masculino & 0,0 & 16,7 & 47,9 & 20,8 & 14,6 & 100,0 \\
\hline
\end{tabular}

Fuente: Elaboración propia.

Tabla 8. Nivel de aceptación de la afirmación M5:

"A las chicas se les hace difícil aprender a programar", según género (\%)

\begin{tabular}{lcccccc}
\hline & $\begin{array}{c}\text { Muy de } \\
\text { acuerdo }\end{array}$ & $\begin{array}{c}\text { De } \\
\text { acuerdo }\end{array}$ & $\begin{array}{c}\text { Ni de acuerdo } \\
\text { ni en } \\
\text { desacuerdo }\end{array}$ & $\begin{array}{c}\text { En } \\
\text { desacuerdo }\end{array}$ & $\begin{array}{c}\text { Muy en } \\
\text { desacuerdo }\end{array}$ & Total \\
\hline Femenino & 4,0 & 12,0 & 12,0 & 24,0 & 48,0 & 100,0 \\
Masculino & 2,1 & 12,5 & 50,0 & 25,0 & 10,4 & 100,0 \\
\hline
\end{tabular}

Fuente: Elaboración propia.

Tabla 9. Nivel de aceptación de la afirmación M6:

"Las chicas no podrían crear un videojuego", según género (\%)

\begin{tabular}{ccccccc}
\hline & $\begin{array}{c}\text { Muyde } \\
\text { acuerdo }\end{array}$ & $\begin{array}{c}\text { De } \\
\text { acuerdo }\end{array}$ & $\begin{array}{c}\text { Ni de acuerdo } \\
\text { ni en } \\
\text { desacuerdo }\end{array}$ & $\begin{array}{c}\text { En } \\
\text { desacuerdo }\end{array}$ & $\begin{array}{c}\text { Muy en } \\
\text { desacuerdo }\end{array}$ & Total \\
\hline Femenino & 0,0 & 0,0 & 4,0 & 16,0 & 80,0 & 100,0 \\
Masculino & 2,1 & 8,3 & 16.7 & 25,0 & 47,9 & 100,0 \\
\hline
\end{tabular}

Fuente: Elaboración propia. 
No obstante, los valores cambian en el caso de las afirmaciones negativas de las mujeres (Tablas 7, 8 y 9): se puede observar que la mayoría de alumnas rechazan tales afirmaciones ("Muy en desacuerdo" y "En desacuerdo"), mientras que la mayoría de los hombres prefieren asumir una posición neutral ("Ni de acuerdo ni en desacuerdo"). Por ejemplo, el 64\% de las mujeres rechazan no ser hábiles en el curso de informática - la afirmación M4 (Tabla 7)-. En contraste, solo el $35,4 \%$ de los hombres rechaza esta afirmación y el $47,9 \%$ opta por situarse en una posición neutral. Solo en la afirmación M6 (Tabla 9) existe un elevado rechazo hacia la idea de que las mujeres no podrían crear un videojuego, tanto de parte de los hombres (72,9\%) como de las mujeres (96\%). Este resultado se puede explicar debido a que en el tercer bimestre los/as estudiantes realizaron un videojuego para el curso. Con ello, el estereotipo se pudo haber visto cuestionado, pues los hombres experimentaron de cerca las habilidades de sus pares femeninas en la actividad propuesta.

\section{- Percepciones sobre los hombres}

Las tablas presentadas a continuación presentan información sobre cómo son percibidos por hombres, de acuerdo con el género de las personas entrevistadas.

Tabla 10. Nivel de aceptación de la afirmación H1:

"Los chicos son buenos en los cursos de informática”, según género (\%)

\begin{tabular}{lcccccc}
\hline & $\begin{array}{c}\text { Muy en } \\
\text { desacuerdo }\end{array}$ & $\begin{array}{c}\text { En } \\
\text { desacuerdo }\end{array}$ & $\begin{array}{c}\text { Ni de acuerdo } \\
\text { ni en } \\
\text { desacuerdo }\end{array}$ & $\begin{array}{c}\text { De } \\
\text { acuerdo }\end{array}$ & $\begin{array}{c}\text { Muy de } \\
\text { acuerdo }\end{array}$ & Total \\
\hline Femenino & 0.0 & 4.0 & 20.0 & 44.0 & 32.0 & 100.0 \\
Masculino & 0.0 & 0.0 & 33.3 & 50.0 & 16.7 & 100.0 \\
\hline
\end{tabular}

Fuente: Elaboración propia.

Tabla 11. Nivel de aceptación de la afirmación H2:

“A los chicos se les hace fácil aprender programas de computación”, según género (\%)

\begin{tabular}{ccccccc}
\hline & $\begin{array}{c}\text { Muy en } \\
\text { desacuerdo }\end{array}$ & $\begin{array}{c}\text { En } \\
\text { desacuerdo }\end{array}$ & $\begin{array}{c}\text { Ni de acuerdo } \\
\text { ni en } \\
\text { desacuerdo }\end{array}$ & $\begin{array}{c}\text { De } \\
\text { acuerdo }\end{array}$ & $\begin{array}{c}\text { Muy de } \\
\text { acuerdo }\end{array}$ & Total \\
\hline Femenino & 0,0 & 0,0 & 40,0 & 40,0 & 20,0 & 100,0 \\
Masculino & 2,1 & 12,5 & 22,9 & 45,8 & 16,7 & 100,0 \\
\hline
\end{tabular}

Fuente: Elaboración propia. 
Tabla 12. Nivel de aceptación de la afirmación H3:

“A los chicos se les hace fácil aprender a programar”, según género (\%)

\begin{tabular}{ccccccc}
\hline & $\begin{array}{c}\text { Muy en } \\
\text { desacuerdo }\end{array}$ & $\begin{array}{c}\text { En } \\
\text { desacuerdo }\end{array}$ & $\begin{array}{c}\text { Ni de acuerdo } \\
\text { ni en } \\
\text { desacuerdo }\end{array}$ & $\begin{array}{c}\text { De } \\
\text { acuerdo }\end{array}$ & $\begin{array}{c}\text { Muy de } \\
\text { acuerdo }\end{array}$ & Total \\
\hline Femenino & 0,0 & 4,0 & 48,0 & 28,0 & 20,0 & 100,0 \\
Masculino & 2,1 & 8,3 & 43,8 & 33,3 & 12,5 & 100,0 \\
\hline
\end{tabular}

Fuente: Elaboración propia.

$\mathrm{Al}$ observar las tablas 10 y 11 , se puede identificar que ambos géneros tienen una aceptación relativamente alta de las percepciones positivas. Incluso, en el caso de la afirmación H1: "Los chicos son buenos en los cursos de informática", resalta que la aceptación por parte de las mujeres es mayor (76\%) que la de los hombres (66,7\%). Sin embargo, en el ítem H3: "A los chicos se les hace fácil aprender a programar" (Tabla 12), los valores de aceptación ("Muy de acuerdo", "De acuerdo") cambian tanto para los hombres (45,8\%) como para las mujeres (48\%). Es importante observar, en comparación con otros ítems, la manera en que la confianza de los hombres disminuye, lo que indicaría que no todos los hombres poseen facilidad para la programación o, en todo caso, no todos sienten que encajan dentro de ese estereotipo. Es importante contrastar este resultado con el de la Tabla 3, que muestra cierto porcentaje de hombres que presentan dificultades en dicha asignatura.

Tablas 13. Nivel de aceptación de la afirmación H4:

"A los chicos les cuesta crear presentaciones de Power Point de forma creativa", según género (\%)

\begin{tabular}{ccccccc}
\hline & $\begin{array}{c}\text { Muy de } \\
\text { acuerdo }\end{array}$ & $\begin{array}{c}\text { De } \\
\text { acuerdo }\end{array}$ & $\begin{array}{c}\text { Ni de acuerdo } \\
\text { ni en } \\
\text { desacuerdo }\end{array}$ & $\begin{array}{c}\text { En } \\
\text { desacuerdo }\end{array}$ & $\begin{array}{c}\text { Muy en } \\
\text { desacuerdo }\end{array}$ & Total \\
\hline Femenino & 4,0 & 20,0 & 52,0 & 20,0 & 4,0 & 100,0 \\
Masculino & 4,2 & 18,8 & 25,0 & 43,8 & 8,3 & 100,0 \\
\hline
\end{tabular}

Fuente: Elaboración propia. 
Tabla 14. Nivel de aceptación de la afirmación H5:

"A los chicos se les hace más difícil editar videos", según género (\%)

\begin{tabular}{ccccccc}
\hline & $\begin{array}{c}\text { Muy de } \\
\text { acuerdo }\end{array}$ & $\begin{array}{c}\text { De } \\
\text { acuerdo }\end{array}$ & $\begin{array}{c}\text { Ni de acuerdo } \\
\text { ni en } \\
\text { desacuerdo }\end{array}$ & $\begin{array}{c}\text { En } \\
\text { desacuerdo }\end{array}$ & $\begin{array}{c}\text { Muy en } \\
\text { desacuerdo }\end{array}$ & Total \\
\hline Femenino & 4,0 & 4,0 & 24,0 & 36,0 & 32,0 & 100,0 \\
Masculino & 0,0 & 6,3 & 27,1 & 43,8 & 22,9 & 100,0 \\
\hline
\end{tabular}

Fuente: Elaboración propia.

Tabla 15. Nivel de aceptación de la afirmación H6:

"A los chicos no les gusta decorar mucho sus presentaciones en Power Point", según género $(\%)$

\begin{tabular}{ccccccc}
\hline & $\begin{array}{c}\text { Muy de } \\
\text { acuerdo }\end{array}$ & $\begin{array}{c}\text { De } \\
\text { acuerdo }\end{array}$ & $\begin{array}{c}\text { Ni de acuerdo } \\
\text { ni en } \\
\text { desacuerdo }\end{array}$ & $\begin{array}{c}\text { En } \\
\text { desacuerdo }\end{array}$ & $\begin{array}{c}\text { Muy en } \\
\text { desacuerdo }\end{array}$ & Total \\
\hline Femenino & 28,0 & 32,0 & 20,0 & 12,0 & 8,0 & 100 \\
Masculino & 10,4 & 22,9 & 35,4 & 25,0 & 6,3 & 100 \\
\hline
\end{tabular}

Fuente: Elaboración propia.

En relación con las afirmaciones negativas, en el ítem H4: "A los chicos les cuesta crear presentaciones Power Point de forma creativa" existe cierto rechazo, sobre todo, por parte de los hombres (54\%). En este caso, más bien, se nota cierta neutralidad por parte de las mujeres (50\%); la otra mitad de mujeres o bien los rechaza o bien lo acepta (Tabla 13). En el ítem H6: "A los chicos no les gusta decorar mucho sus presentaciones en Power Point", los hombres se encuentran divididos entre rechazar la afirmación $(31,3 \%)$, ser neutrales $(35,4 \%)$ y aceptarla (33,3\%). En contraste, las mujeres muestran una mayor aceptación de la afirmación con un $60 \%$. Estos resultados podrían dar indicios de que la poca decoración de parte de los hombres no es una cuestión de capacidad, sino de gusto, lo cual podría estar siendo influenciado por los estereotipos que se abordarán en la siguiente sección. 


\section{Estereotipos de género y uso de tecnologías}

A continuación, se expondrán los estereotipos de género que se han encontrado en relación con el uso de las tecnologías. La sección se dividirá en función de las tres dimensiones de los estereotipos encontrados: lo académico, lo creativo y lo tecnológico.

\section{- Estereotipos de género en relación con lo académico}

En el ámbito académico, se ha generado la idea de que las mujeres poseen un alto rendimiento y un comportamiento ejemplar durante las clases, pues no se distraen y tampoco generan desorden. Al preguntarle a cada estudiante por tres características que les atribuyen a las mujeres, los adjetivos que sobresalieron fueron responsabilidad, inteligencia, perfeccionismo y enfocadas. Esta idea tiene un efecto en el uso que les dan a las tecnologías, como se puede evidenciar en el testimonio de Rubén, quien considera que el hecho de que los PPT de las mujeres sean "mejores" responde a que son más dedicadas al estudio:

Rubén: Bueno, ciertamente, el de las chicas son más preparadas. Es decir, se preparan más, es decir, desde aprenderse el PPT, hasta cómo está diseñado, ¿no? Pero tampoco es que hay una gran diferencia.

Entrevistador: (.) y ¿a qué crees que se deba eso?

Rubén: A que la mayoría de las chicas son más dedicadas a los estudios en general. Mientras que varios chicos prefieren estar haciendo otras actividades que estar estudiando. (entrevista a Rubén, estudiante)

De la misma manera, esta idea de que las mujeres son buenas en el ámbito académico no solo es interiorizado por estudiantes, sino que el grupo de docentes también manejan estos esquemas. Han expresado que, en la medida que las mujeres tienen mayor grado de madurez, tienen una predisposición a concentrarse más en los estudios, y dejar de lado la distracción y el juego:

Hay una cosa que se da siempre: que son las mujeres más maduras que los hombres y muchas veces se ve el nivel de responsabilidad mucho más alto (.) Ya. Ehh (.) Yo no sé con temor a no equivocarme, te digo que cuando pasen a Mayores $^{29}$, las chicas van a responder de una manera distinta, ¿no? O sea, van a haber más primeros puestos ehh, mujeres que varones. (entrevista a Idilio, profesor de Informática)

29. El segundo grado de secundaria se ubica en una sección del colegio que se denomina "Medianos", junto con sexto de primaria y primero de secundaria. El nivel de "Mayores" comprende los grados de tercero, cuarto y quinto de secundaria, y se ubica al costado del patio de "Medianos". 
Adicionalmente al hecho de que se vea a las mujeres como más responsables y estudiosas, también se las concibe como más tranquilas y calmadas. Dentro de esta concepción, por lo general, se considera que son más centradas en sus estudios y no se distraen con otras actividades en las chromebooks durante las clases. Sin embargo, esto podría deberse, también, al número reducido de mujeres que existe, puesto que - como lo comenta Antonela- siente que la vigilancia es mayor:

la verdad que las chicas en el uso de las chromebooks han mantenido una compostura, porque somos pocas $y$, al ser pocas como que se marca más, si las chicas hacen algo es como que más marcado. [...] son como que 90 chicos contra 30 chicas, y como que ya 90 chicos 2 de ellos ya habrán hecho algo; entonces, como que se marca menos. Entonces, como que nosotras siempre tenemos el cuidado de cuidar las chromebooks y eso. (Entrevista a Antonela, estudiante)

Si bien no se ha podido encontrar que esta sensación de vigilancia esté extendida en todas las mujeres, sí es importante tomarla en consideración. Al ser un colegio con una tradición masculina amplia, lo novedoso puede ser visto con cierta sospecha y, por ende, la vigilancia puede, indirectamente, ser mayor. No obstante, a pesar de que las mujeres han mostrado cierto grado de distracción, ello es visto como una conducta "atípica" por sus pares y por sus docentes. En este sentido, se cumple lo que menciona González Gabaldón (1999), quien afirma que las acciones que perpetúan el estereotipo serán más recordadas que aquellas que las contradicen. En ese sentido, desde los ojos de estudiantes y de docentes, se perpetúa el estereotipo de las mujeres como buenas académicamente, tranquilas y no distraídas.

Por el contrario, el estereotipo masculino se construye en contraposición al femenino y posiciona a los hombres como menos maduros, más propensos a las distracciones (sobre todo, tecnológicas) y poseedores de un menor rendimiento académico - $\mathrm{O}$, al menos, no tan alto como el de las mujeres-. El desarrollo de este estereotipo lleva a que algunos docentes, como el de Matemática, prefieran no incorporar con frecuencia las tecnologías en el aula, pues presiente ("sabe") que el alumno se distraerá:

Mi opinión personal, mas no profesional, es que no se le debió dar una chromebooks a cada alumno, ehh a esta edad. porque su prioridad es la diversión, es el juego, es la, es el vacilón. Sobre todo con la fuerza que tienen los juegos en red, ¿no? ehh muchos chicos desgastan mucho tiempo en buscar o desbloquear un juego ¿no? creen que lo van a lograr (.) y quieren ser hackers ¿no? (entrevista a Marlon, profesor de Matemática)

Finalmente, es importante resaltar que, en el grupo de docentes, el estereotipo de académico/tranquilo es un estereotipo positivo ("bueno"). Sin 
embargo, entre los estudiantes hombres, la tranquilidad parece no ser un factor de prestigio. Más bien, el ser un sujeto distractor convierte al estudiante en alguien "respetado". Según los testimonios recogidos de los y las estudiantes, la sanción ya no es vista como algo "malo", sino como una señal de prestigio. Como comentaba una alumna, incluso algunos hombres se sacrifican para ser amonestados, a pesar de no ser ellos quienes cometieron la falta:

[...] comenzó con un chico que lo llevaron a donde Saúl [el coordinador] por hacer mal uso de las chromebooks, y cuando llegó al salón, lo trataban como el rey el líder, el jefe, y como que le hacían como que, le daban mucha bola [...]. (Entrevista a Antonela, estudiante)

De esta forma, se refuerza la idea de que los hombres poseen un mayor margen de libertad para poder trasgredir las normas, sin que ello suponga un castigo social extremadamente drástico, en tanto se considera que es parte de su comportamiento regular. En cambio, en el caso de las mujeres, su margen de acción para la trasgresión es limitado. Esto se debe a que ellas sienten que la transgresión será juzgada, sobre todo, en un ambiente en donde numéricamente son menos y sienten, en algunos casos, cierto grado de vigilancia.

\section{- Estereotipos de género en relación con lo creativo}

Un segundo ámbito de los estereotipos que se pudo identificar se relaciona con la creatividad o el quehacer creativo. Este estereotipo establece una dicotomía entre los diversos elementos estéticos que utilizan las mujeres para realizar presentaciones o crear videojuegos, y pocos elementos creativos que los hombres emplean para el mismo fin. En este sentido, las mujeres se esfuerzan más en buscar nuevos elementos para sus presentaciones con aplicaciones complementarias, como Slides Carnival ${ }^{30}$ :

Pero la mayoría de chicas, o sea, no le gusta mucho; le gusta ser más como que poner más detalles. Una compañera me mostró una página donde te aparecían varios como temas para las presentaciones de Google, si no te gustaban las determinadas ya de por sí. Y que podías descargar y empezar a utilizar para que tu presentación salga más didáctica y divertida. (Entrevista a Julio, estudiante)

Por su lado, las habilidades creativas de los hombres están subvaloradas, pues, si bien ellos poseen creatividad para la elaboración de videojuegos complejos con distintos niveles y elementos visuales bastante desarrollados, sus

30. Slice Carnival es una página web que desarrolla diversos tipos de plantillas para el Power Point o las presentaciones de Google. Para mayor información, se puede ver su web oficial: https://www.slidescarnival.com/es 
presentaciones son vistas como "simples", "poco estéticas". Se considera que solamente utilizan los recursos básicos para expresar una idea:

No, las chicas los hacen mm... lo embellecen más, y los chicos lo hacen más simple, la mayoría. La mayoría de los chicos una plantilla cualquiera ehh no sé, Arial negro 12, así todo todo todos, un texto con un párrafo gigante, pegas una foto, así. En cambio, las chicas lo hacen más bonito. No sé, le ponen color, le ponen tipo de letra, le ponen foto todo. Claro, hay diseñadores también de chicos, pero hay una buena cantidad del salón que solo hace eso, pone una plantilla y por defecto le pone. (Entrevista a Augusto, estudiante)

Esto genera una división de la creatividad en dos partes. Por un lado, se encuentra la creatividad asociada a los detalles, predominantemente relacionada con el género femenino por medio del desarrollo de diversos elementos que decoran las presentaciones, y permiten que el mensaje se transmita y tenga un efecto de "belleza/armonía" en el espectador. Por otro lado, se construye la noción de una creatividad vinculada al desarrollo de ideas: la elaboración de juegos con una gran cantidad de elementos, como armas, escenarios, distintos niveles de complejidad, etc. Esta creatividad, más bien, se asocia principalmente con el género masculino. En el primer caso, la creatividad se relaciona con la estética y la armonía, y, por ende, con las mujeres. En el segundo caso, está ligada a las ideas novedosas de los hombres para crear videojuegos.

Esta concepción de creatividad más estética se pudo evidenciar al momento en que las mujeres creaban sus videojuegos. A diferencia de los hombres, que diseñaban personajes con mayor velocidad, las mujeres se tomaban el tiempo para crear a los personajes con una gran cantidad de detalles:

Las chicas del Grupo 6 se han pasado toda la clase creando y dibujando a los personajes con colores y creándolos desde cero. Los detalles a los personajes son interesantes y están muy bien definidos cada una de sus partes, presentan distintos colores y parecen estar bien diseñados. (Registro de observación participante 7, clase de Informática)

Asimismo, en los siguientes extractos de los resúmenes técnicos de dos videojuegos ganadores de la Feria de Innovación Tecnológica del colegio, se puede observar las diferencias entre el diseño del grupo de hombres (Documento 1) y el de mujeres (Documento 2):

El Personaje principal es un Ninja (el cual debe sobrevivir) y el personaje secundario es un boss enemigo (un robot futurista), el cual aparecerá al final, para intentar asesinar al ninja. (Documento 1, juego "El regreso del ninja"31)

31. El nombre original, en inglés, era The Return of the Ninja. 
Personaje 1 (Chica tímida) Pelo negro, lentes y nerd.

Personaje 2 (Chica popular) Pelo castaño, es una porrista.

Personaje 3 (Chica rebelde) Pelo rubio, tatuajes y piercings.

Personaje 4 (Chica alegre) Pelo castaño, vestido, siempre sonríe [...] (Documento 2, juego "La vida de una adolescente"32)

Si bien ambos videojuegos son, de por sí, "creativos", se puede observar claramente la diferencia entre los tipos de creatividad detallados previamente. Las mujeres tienden a desarrollar con mayor énfasis las descripciones y los detalles de los personajes. En contraste, los hombres construyen personajes funcionales al juego, pues su interés no radica tanto en cómo se ven, sino en el fin que cumplen en la historia. Esto no necesariamente impide que el resto del videojuego no haya sido elaborado con detenimiento, solo que las preferencias de ambos géneros están enfocadas en dos procesos creativos distintos: elaboración de personajes y paisajes (mujeres), por un lado, y programación y dificultad del juego (hombres), por el otro. Es importante mencionar que, aunque estas dicotomías se encuentran presentes en la mayoría de los casos observados, existen grupos (tanto de hombres como de mujeres) que desafían el estereotipo y les dan importancia a ambos procesos por igual.

\section{- Estereotipos de género en relación con la tecnología}

Este estereotipo se construye en dos partes. En la primera, se piensa que los hombres están acostumbrados a las tecnologías, porque desde pequeños se les ha inculcado el gusto por ellas a través del consumo de videojuegos. En consecuencia, en la segunda parte, se establece que esta "costumbre" o este "hábito" genera que ellos tengan una mayor habilidad tecnológica. El testimonio de Antonia lo manifiesta así:

[...] ellos como que pasan más tiempo en la computadora en las casas, por ejemplo, ehh pasan jugando tiempo tras tiempo o en cada momento, justo ahora en las chromebooks, juegan y hacen. Entonces tienen más habilidad, más, participan más rápido, más que nada como que más juegan están más pegados a las chromebooks o a las computadoras. Tienen más habilidades con los dedos y supongo que es más fácil para ellos. (Entrevista a Antonia, estudiante)

En contraposición, el estereotipo sobre las mujeres y la tecnología se construye a partir de la ausencia de este "hábito" o "costumbre", lo que hace que posean habilidades tecnológicas menos desarrolladas, como lo expresa Josué:

32. El nombre original, en inglés, era A Teenager's Life. 
Hmm yo creo que, como que no, o sea como no han tenido mucha experiencia con los videojuegos, entonces, ehmm les puede ser difícil un poco lo que es programar videojuegos, porque como que no saben mucho. Y, como que los hombres se les puede hacer más fácil porque muchas veces están jugando con sus amigos, así. (Entrevista a Josué, estudiante)

Si bien algunos/as estudiantes manifiestan estas asociaciones de manera más directa, esto no ocurre en todos los casos, en tanto existe la idea de que expresar estos estereotipos "está mal". A pesar de ello, se manifiestan indirectamente en ciertos discursos, como el de Álvaro. Este estudiante, por un lado, trata de refutar el estereotipo y menciona que esto es falso, pues conoce compañeras que sí dominan las tecnologías; sin embargo, al final de la entrevista, afirma que una de las características que les atribuye a los hombres es la de poseer mayores habilidades tecnológicas:

Y este, a los chicos, este (.) habilidosos ehhhmm, ¿qué más? también responsables en ciertos casos, y (.) ehhmm, ¿qué más, qué más qué más? ahhh (..) también podría decir dinámicos con los trabajos que hacen, son características que se comparten ¿no?, pero cierto en los chicos esto hay un poco de habilidad al momento de usar las computadoras. (Entrevista a Álvaro, estudiante)

El estereotipo no solo es reforzado por el grupo de estudiantes, quienes lo tienen incorporado. También, es reproducido por algunos docentes, quienes plantean que las mujeres pueden tener mayores dificultades en los temas tecnológicos, debido a que no están acostumbradas a dominarlos. A diferencia de ellas, consideran los hombres sí dominan dichos temas al estar en constante interacción con las tecnologías:

Ahora en lo que es mi curso, Ciencias de la Computación, sí, los chicos son los que están más orientados a, a destacar, ¿Por qué? Porque estamos viendo algo que les gusta, algo que les agrada. Y que ha sido con una doble intención ¿no? Este, producir juegos ehh, son los chicos que más juegan. Con las chicas sí sentí no iba a encontrar esa receptividad, y se evidenció con algunos proyectos, que felizmente, han salido interesantes ¿no? (Entrevista a profesor de Informática)

Para el docente, el plantear una actividad sobre la creación de un videojuego les resultaría más fácil a los hombres, pues es su "ambiente natural". Por ello, el profesor sugiere que una solución sería que las mujeres puedan realizar historias gráficas, en lugar de un videojuego tradicional para evitar que no se sientan "incómodas" elaborándolo. No obstante, para algunas alumnas, el ofrecimiento de esta posibilidad les generó molestia, puesto que ellas también se 
consideran capaces de crear videojuegos. En este sentido, la acción del profesor estaba atentando contra su libertad de poder realizar la misma actividad que los hombres:

[...] el profesor decía como que "las chicas, no es necesario que hagan un juego porque no les va muy bien en la tecnología", pero no me parece porque tenemos la misma capacidad y también hay varias chicas, sobre todo en esta promoción, le gustan los videojuegos. Juegan videojuegos y no es necesario como que ser hombre o mujer para poder jugar o saber hacerlo. (Entrevista a Antonela, estudiante)

De esta manera, Antonela y su grupo decidieron no cumplir lo que el profesor les sugería y realizar un videojuego en que retrataban un día en segundo grado de secundaria con docentes que tenían poderes y que, a través de laberintos, debían defenderse de los monstruos, que eran estudiantes. De este modo, lograron desafiar el estereotipo que el docente, indirectamente, quería perpetuar y reproducir sobre ellas.

\section{Conclusiones}

En esta investigación, se ha corroborado que los estereotipos tradicionales de género persisten aun con la inclusión de tecnologías en el aula. Las diferencias de género se manifiestan en los tres tipos de uso de las tecnologías planteados: el operacional, el creativo y el recreativo. En el uso operacional, se puede observar que existen ligeras diferencias entre hombres y mujeres en los programas de procesamiento de números y de programación, mas no en los de procesamiento de texto, en el que ambos géneros demuestran destreza tecnológica. En el uso creativo, se puede observar que las mujeres utilizan más elementos estéticos para decorar sus presentaciones, mientras los hombres generan presentaciones simples y poco elaboradas. Asimismo, en lo que respecta a la creación de videojuegos, se evidencia que las temáticas son distintas: los hombres elaboran videojuegos con un gran componente de violencia, a diferencia de las mujeres, que exploran otras temáticas (entretenimiento, aventura, etc.).

En cuanto al uso recreativo, se pudieron identificar diferencias en las actividades que realizan en sus tiempos libres en el aula: los hombres juegan videojuegos, mientras que las mujeres prefieren ver series o películas en Netflix o en YouTube. Adicionalmente, se puede evidenciar que el género masculino presenta mayores distracciones durante las clases, en las que tienden a emplear las chromebooks para jugar. Si bien las mujeres también se distraen, este comportamiento no es constante y podría estar siendo influenciado por la sensación de vigilancia que sienten debido a que son minoría (representan un tercio del total de estudiantes).

En cuanto a las percepciones sobre el uso de las TIC entre hombres y mu-

118 I jeres, se puede observar que existe cierta asociación entre el género masculino 
y las tecnologías. Sin embargo, también hay un rechazo hacia afirmaciones que establecen que a las mujeres les cuesta desarrollarse en el ámbito tecnológico. Cabe anotar que este rechazo no es homogéneo y que son las propias mujeres quienes manifiestan su rechazo hacia dichos estereotipos. Los hombres, por su parte, manifiestan respuestas divididas entre estar de acuerdo, ser neutrales y estar en desacuerdo con los estereotipos planteados.

Se pudieron identificar tres ámbitos en los cuales los estereotipos de género tradicionales persisten con el uso de las TIC: en el ámbito académico, en el ámbito creativo y en el ámbito tecnológico. En el primero, se puede afirmar que existe un estereotipo "positivo" y altamente valorado por el grupo de docentes hacia las mujeres: las consideran maduras, responsables y académicamente superiores a los hombres. En contraposición, el estereotipo que se tiene de los hombres es que su madurez es menor, y se distraen con mayor facilidad al momento de utilizar las TIC. En el ámbito de la creatividad, se identificó que los estereotipos asociados a las mujeres es que son más detallistas y le dan más valor a lo estético. Por el contrario, las habilidades creativas de los hombres se encuentran subvaloradas, pues, si bien son capaces de generar videojuegos novedosos, se considera que son simplistas, poco detallistas, y que poseen un valor de la estética poco desarrollado al momento de utilizar las TIC. Finalmente, en relación con la tecnología, se identifica el estereotipo de que los hombres presentan mayores facilidades y son mejores en los temas tecnológicos que las mujeres. Esta idea surge en la medida que se cree que el contacto que tienen con las TIC desde pequeños es mayor y que, por ende, les es muy fácil adaptarse a un contexto tecnológico en el colegio.

En síntesis, la incorporación de las tecnologías de la información y comunicación (TIC) en un contexto de clase media urbano y capitalino perpetúan los estereotipos de género ya existentes; lejos de eliminarlos, los reproducen. No obstante, también tienen la capacidad de generar ciertos mecanismos de resistencia y/o cuestionamiento, en la medida que les permiten a las alumnas estar en contacto con actividades tecnológicas que tradicionalmente han sido asociadas a los hombres (como diseñar videojuegos).Si bien no se puede concluir que los estereotipos de género condicionan o son la causa de los usos diferenciados de la tecnología, sí se identifica que existe una relación que se va retroalimentando, en la que los estereotipos se perpetúan a través de la tecnología, mientras que, a su vez, esta genera los mecanismos para reproducirlos y cuestionarlos.

\section{Agradecimientos}

Quisiera agradecer a Rocío Trinidad Zapata por su asesoría a lo largo de todo este proceso de investigación y su constante enseñanza. Asimismo, quisiera agradecer a la institución educativa por abrirme las puertas para realizar la investigación. 


\section{Referencias bibliográficas}

Ames, P. (2014). Niños y adolescentes frente a las nuevas tecnologías: Acceso y uso de las tecnologías educativas en las escuelas peruanas. Revista Peruana de Investigación Educativa, (6), 145-172.

Area, M. (2005). Tecnologías de la información y comunicación en el sistema escolar. Una revisión de las líneas de investigación. Relieve: 11(1), 3-25.

(2010). El proceso de integración y uso pedagógico de las TIC en los centros educativos: Un estudio de casos. Revista de Educación, (352), 7797.

Barreto, M., García, A., y Asensio, Raúl H. (2013). Control y trasgresión. El uso, apropiación e impacto de las TIC por las mujeres rurales jóvenes en el Perú. Lima: IEP y Nuevas Trenzas.

Basile, D., y Linne, J. (2013). Usos escolares de Internet en adolescentes de sectores populares. Espacio Abierto Cuaderno Venezolano de Sociología, 22(3), 477-487.

Belmonte-Arocha, J., y Guillamón-Carrasco, S. (2008). Co-educating the gaze against gender stereotypes in TV. Comunicar, 16(31), 115-120. https://doi. org/10.3916/c31-2008-01-014

Buendía García, F., Benlloch Dualde J., Zahonero Viana, I., y Cubel Barea, A. (2016). Experiencias en la aplicación de tabletas en Secundaria. EKS, 17(4), 75-89.

Castro Balsa, J., y Trigo, X. (2017). Los estereotipos de género y las TICs en estudiantes de secundaria. Revista de Estudios e Investigación en Psicología y Educación, (13), 144-148. https://doi.org/10.17979/reipe.2017.0.13.2585

Choque, R. (2009). Eficacia en el desarrollo de capacidades TIC en estudiantes de Educación Secundaria de Lima, Perú. Revista de Medios y Educación, (35), 5-20.

Cussó, R. (2014). Género y actitudes ante las TIC: Estudio de la influencia del uso de ordenadores personales en los centros escolares (Tesis de maestría). Universitat de Lleida, Lérida.

Cussó-Calabuig, R., Carrera Farran, X., y Bosch-Capblanch, X. (2017). Are boys and girls still digitally differentiated? The case of Catalonian teenagers. Journal of Information Technology Education: Research, 16, 411435. https://doi.org/10.28945/3879

Evaristo Chiyong, I., Navarro Fernández, R., Vega Velarde, V., y Nakano Osores, T. (2016). Uso de un videojuego educativo como herramienta para aprender historia del Perú. RIED: Revista Iberoamericana de Educación a Distancia, 19(2), 35-52.

Ferreira, E. (2017). The co-production of gender and ICT: Gender stereotypes in schools. First Monday, 22(10). https://doi.org/10.5210/fm.v22i10.7062 
García, A.,yGonzálezR.(s.f.).Usopedagógico dematerialesyrecursoseducativos de las TIC: Sus ventajas en el aula. Recuperado de http://2633518-0.webhosting.es/blog/didact_mate/6.\%20Uso $\% 20$ Pedag $\%$ C3\%B3gico $\% 20$ de $\% 20$ Materiales $\% 20 y \% 20$ RecursosEducaticvos\%20de $\% 20$ las $\% 20$ TIC.\%20Sus\%20Ventaja\%20en\%20el\%20Aula\%20TIC\%20\%282\%29.pdf

Gargallo-Castel, A., Esteban-Salvador, L., y Pérez-Sanz, J. (2010) Impact of gender in adopting and using ICTs in Spain. Journal of Technology Management \& Innovation, (5), 120-128.

González Gabaldón, B. (1999). Los estereotipos como factor de socialización en el género. Comunicar, (12), 79-88.

Gutiérrez García, G. (2010) El uso de las laptops XO en el área de Comunicación Integral en alumnos de educación primaria de una escuela rural en la región Junín- Perú. Educación, 19(37), 67-86.

Hall, S., Restrepo, E., Walsh, C., y Vich, V. (2010). Sin garantías: Trayectorias y problemáticas en estudios culturales. Bogotá: Envíon Editores, Instituto de Estudios Peruanos, Instituto de Estudios Sociales y Culturales, Pensar, Universidad Javeriana, Universidad Andina Simón Bolívar - Sede Ecuador.

Hernández, L., Acevedo, J. A. S., Martínez, C., y Cruz, B. C. (2015). El uso de las TIC en el aula: Un análisis en términos de efectividad y eficacia. En J. Asenjo, O. Macías y J. C. Toscano (Eds.), Memorias del Congreso Iberoamericano de Ciencia, Tecnología, Innovación y Educación. Buenos Aires: OEI.

Instituto Nacional de Estadística e Informática (2017a). Características de la Vivienda y del Hogar: Anual [Base de datos]. Recuperado de http://iinei. inei.gob.pe/microdatos/

(2017b). Encuesta Nacional a Instituciones Educativas - Enedu [Base de datos]. Recuperado de http:// escale.minedu.gob.pe/enedu-2017

(2018a). Características de la

Vivienda y del Hogar: Trimestre 3 [Base de datos]. Recuperado de http:// iinei.inei.gob.pe/microdatos/

(2018b).Educación: Trimestre

3 [Base de datos]. recuperado de http://iinei.inei.gob.pe/microdatos/

Johnson, R. B., y Onwuegbuzie, A. J. (2004). Mixed methods research: A research paradigm whose time has come. Educational Researcher, 33(7), $14-26$.

Ministerio de Educación (2017). Currículo Nacional de la Educación Básica, Lima: Ministerio de Educación.

Morales, E. (2018). Desigualdades digitales: edad, género y tecnologías de la información y comunicación en la costa norte del Perú (tesis de 
licenciatura). Pontificia Universidad Católica del Perú, Facultad de Ciencias Sociales, Lima.

Morris, D., y Trushell, J. (2014). Computer programming, ICT and gender in the classroom: a male-dominated domain or a female preserve? Research In Teacher Education, 4, 4-9.

Pechtelidis, Y., Kosma,Y., y Chronaki, A. (2015) Between a rock and a hard place: women and computer technology. Gender and Education 27(2), 164-182. http://dx.doi.org/10.1080/09540253.2015.1008421

Pérez Sedeño, E. (2008). Mitos, creencias, valores: cómo hacer más "científica" la ciencia; cómo hacer la "realidad" más real. Isegoría. Revista de Filosofía Moral y Política, (38), 77-100.

Rodríguez-López, J. (2015). La difusión de los estereotipos de género a través de las TIC: La mujer en el vídeo musical. Ámbitos: Revista Internacional de Comunicación (25), 1-13.

Santiago, A., Severin, E., Cristia, J., Ibarrán, P., Thompson, J., y Cueto, S. (2010). Evaluación experimental del programa "Una Laptop Por Niño" en Perú. Aportes, (5), 1-12.

Schaumburg H. (2001). Fostering girls' computer literacy through laptop learning: Can mobile computers help to level out the gender difference? Trabajo presentado en National Educational Computing Conference, "Building on the Future". Chicago, julio 25-27.

Suana, W. (2018). Students' internet access, internet self-efficacy, and internet for learning physics: Gender and grade differences. Journal of Technology and Science Education, 8(4), 281. https://doi.org/10.3926/jotse.399

Talbot, M. (2003). Gender stereotypes: Reproduction and challenge. En J. Holmes y M. Meyerhoff (Eds.), The handbook of language and gender (pp.468- 486). Malden, MA: Blackwell.

Thomas, T., y Allen, A. (2006). Gender differences in students' perceptions of information technology as a career. Journal of Information Technology Education, 5, 165-178.

Trinidad, R. (2005). Entre la ilusión y la realidad: las nuevas tecnologías en dos proyectos educativos del estado. Lima: Instituto de Estudios Peruanos.

Trinidad, R., y Zlachesvsky, N. (2013). Jugar en contextos tecnológicos: Uso y disfrute de internet por niños y niñas de 8 a 10 años en Argentina, Paraguay y Perú. Contratexto, (21), 211-227. 